\title{
CONTROLE POPULACIONAL DO MOSQUITO AEDES AEGYPTI UTILIZANDO SOLUÇÕES CONTENDO ÓLEOS ESSENCIAIS DE PLANTAS DA CAATINGA E METARHIZIUM ANISOPLIAE
}

\author{
J. V. O. ALVES ${ }^{1}$; J. S. LIMA ${ }^{1}$; D. S. J. SILVA ${ }^{1} ;$ M. R. C, LIMA ${ }^{1}$; P. M. SILVA ${ }^{1}$; \\ J. W. L. M. SILVA ${ }^{1}$; W. K. COSTA ${ }^{1}$; G. C. SILVA ${ }^{1}$; L. C. AMORIM ${ }^{1}$; A. G. SILVA ${ }^{1}$, \\ M. V. SILVA ${ }^{1}$; M. T. S. CORREIA ${ }^{1}$. \\ ${ }^{1}$ Universidade Federal de Pernambuco, Centro de Biociências, Departamento Bioquímica. \\ E-mail para contato: jv-bio@hotmail.com
}

\begin{abstract}
RESUMO - $O$ A. aegypti é uma espécie presente no ambiente domiciliar e ela é altamente antropofilica sendo a mais competente para a transmissão da dengue. Uma das maneiras para prevenir as arboviroses que são transmitidas pelo A. aegypti é evitar o nascimento do mosquito, essa estratégia visa o controle vetorial que é baseada no uso de inseticidas que são substâncias de origem natural ou sintética utilizadas para diminuir a incidência de insetos em diferentes fases do seu ciclo de vida. Diversos óleos essenciais apresentam atividade inseticida, incluindo atividade larvicida contra larvas do mosquito A. aegypti. O fungo entomopatogênico Metarhizium anisopliae tem sido considerado potencial no controle desse vetor. Estudos demonstraram o efeito patogênico e virulento de isolados de M. anisopliae sobre o mosquito adulto do A. aegypti, bem como a obtenção de $90 \%$ de mortalidade em larvas utilizando $M$. anisopliae. O presente trabalho tem como objetivo avaliar a suscetibilidade das larvas de A. aegypti à formulação do fungo M. anisopliae combinado com óleos essenciais de Commiphora leptophloes e Eugenia brejoensis. Os resultados desse trabalho se mostraram de altíssima importância tendo em vista a melhoria do processo biotecnológico no controle das larvas do vetor de Aedes aegypti. O efeito sinérgico do entomopatogêno, mais o óleo essencial, aumentou de $30 \%$ à $50 \%$ a mortalidade das larvas, potencializando assim o seu efeito tóxico.
\end{abstract}

Palavras Chaves: Arboviroses, Commiphora leptophloes e Eugenia brejoensis.

ABSTRACT - The A. aegypti is a species present in the home environment and it is highly anthropophilic being the most competent for the transmission of dengue. One of the ways to prevent the arboviruses that are transmitted by A. aegypti is to avoid the birth of the mosquito, this strategy aims vector control that is based on the use of insecticides that are substances of natural or synthetic origin that is used to reduce the incidence of insects at different stages of their life cycle. Several essential oils have insecticidal activity, including larvicidal activity against A. aegypti mosquito larvae. The entomopathogenic fungus Metarhizium anisopliae has been considered a potential in the control of this vector. Studies have shown the pathogenic and virulent effect of $M$. anisopliae isolates on the adult mosquito A. aegypti, as well as obtaining 90\% mortality in larvae using M. anisopliae. The present work aims to evaluate the susceptibility of $A$. aegypti larvae to the 
formulation of the fungus $M$. anisopliae combined with essential oils of Commiphora leptophloes and Eugenia brejoensis. The results of this work were shown to be extremely important in order to improve the biotechnological process in the control of Aedes aegypti vector larvae. The synergistic effect of the entomopathogen plus the essential oil increased larval mortality from 30 to $50 \%$, thus enhancing its toxic effect.

Key words: Arboviroses, Commiphora leptophloes and Eugenia brejoensis

\section{INTRODUÇÃO}

Mosquitos (Família: Culicidae) são de longe os insetos mais exaustivamente pesquisados. Eles provavelmente têm uma influência muito maior sobre a saúde humana e o bem-estar em todo o mundo do que qualquer outro artrópode, principalmente por serem transmissores de uma série de doenças terríveis (como a malária, filariose, dengue, encefalite japonesa, febre do vale do Rift, Chikungunya e febre zika), criando incômodo de grande importância na saúde pública (MEHLHORN et al., 2012; BENELLI, 2015).

A estratégia mais antiga para o controle do vetor e ainda a mais utilizada, é baseada no uso de inseticidas, substâncias de origem natural ou sintética. $\mathrm{O}$ uso contínuo desse larvicida sintético fez com que surgissem populações resistentes, como consequência do uso irracional, além dos efeitos indesejáveis como aumento da frequência de aplicação, dosagens crescentes, permanência por longos períodos de tempo no meio ambiente, afetando os ecossistemas e surgimento de doenças, quando os vetores não podem ser controlados. A resistência aos inseticidas sintéticos é vista como uma ameaça extremamente grave e alternativas são necessárias urgentemente (HEMINGWAY e RANSON, 2000; McCAFFERY e NAUEN, 2006; NAUEN, 2007; WHO, 2012c).

Este problema se tornará o principal impulso para alternativas aos larvicidas sintéticos, o que seria aceitável tanto para o ambiente quanto para saúde humana. Entre as estratégias alternativas existentes que visam diminuir populações de insetos pragas, está a utilização de pesticidas à base de compostos bioativos de plantas, além de microrganismos entomopatogênicos, que, na atualidade, são as alternativas mais promissoras. Diversos óleos essenciais (OE's) apresentam atividade inseticida, incluindo atividade larvicida contra larvas do mosquito $A$. aegypti. O fungo entomopatogênico Metarhizium anisopliae tem sido considerado potencial candidato para os programas de controle de vetores. Paula et al. (2008) demonstraram o efeito patogênico e virulento de isolados de $M$. anisopliae sobre adultos do mosquito $A$. aegypti e Pereira et al. (2009). A presente proposta tem como objetivo avaliar a suscetibilidade das larvas de $A$. aegypti a soluções contendo conídios do fungo $M$. anisopliae combinado com óleos essenciais de Commiphora leptophloes e Eugenia brejoensis.

\section{MATERIAIS E MÉTODOS}

Folhas de C. leptophloeos e E. brejoensis foram coletadas de diferentes espécimes no Parque Nacional do Catimbau (Pernambuco, Brasil). O material vegetal foi levado ao Laboratório de Produtos Naturais, do Departamento de Bioquímica, do Centro de Biociências, da Universidade Federal de Pernambuco. Paralelamente foram coletados ramos férteis para incorporação ao Herbário IPA, do Instituto Agronômico de Pernambuco (IPA). Após a chegada do material vegetal no laboratório, as folhas de $C$. 
leptophloeos e E. brejoensis foram submetidas extração dos óleos essenciais através da técnica de hidrodestilação por 3h (AZMIR et al. 2013).

A identificação química dos compostos presentes no óleo essencial foi realizada por meio da técnica de cromatografia gasosa acoplada ao espectrômetro de massas (CG/EM).

Um isolado de $M$. anisopliae (E6) foi gentilmente cedido pelo Laboratório de Biologia Molecular de Fungos Filamentosos, do Centro de Biotecnologia da Universidade Federal do Rio Grande do Sul. Para verificação de pureza dos conídios, os mesmos foram inoculados em placas de petri em meio ágar nutriente (AN) incubados à $37^{\circ} \mathrm{c}$ para identificar possíveis contaminação por bactérias e em meio batata dextrose ágar (BDA) à $27^{\circ} \mathrm{c}$ para identificar possíveis colônias de outros fungos.

No ensaio de toxidade dos óleos essenciais ao $M$. anisopliea, o fungo foi inoculado na concentração de $1 \times 107$ conídios $/ \mathrm{ml}$ e meio de cultura foi formulado com três concentrações $(10,1$ e $0,1 \mu \mathrm{l} / \mathrm{ml})$ de óleo essencial. As placas ficaram incubadas em câmara climatizada a $27^{\circ} \mathrm{C}$ e $70 \pm 10 \%$ UR. Diariamente, utilizando um paquímetro, foi avaliado o crescimento radial $(\mathrm{cm})$ do fungo durante o período de 7 dias

Para realização da atividade larvicida das soluções contendo os OE's foram avaliadas utilizando-se uma adaptação do método recomendado pela Organização Mundial de Saúde (OMS, 1981) segundo Navarro et al., (2003). O ensaio larvicida do $M$. anisopliae, ele foi cultivado previamente por setes (07) dias em meio BDA para obtenção dos conídios. A partir da raspagem dos conídios foram formuladas três (03) soluções com concentrações $1 \times 10^{9} ; 10^{7}$ e $10^{5}$ conídios $/ \mathrm{ml}$. As soluções foram usadas para infectar as larvas do $A$. aegypti, o tratamento controle foi feito somente com água e tween 80 $(0,01 \%)$. O efeito sinérgico do $M$. anisopliae com os óleos essenciais foi utilizado três (03) soluções contendo a combinação do M. anisopliae $\left(1 \times 10^{9} ; 10^{7}\right.$ e $10^{5}$ conídios $\left./ \mathrm{ml}\right)$ com C. leptophloeos (100 PPM) e três (03) M. anisopliae $\left(1 \times 10^{9} ; 10^{7}\right.$ e $10^{5}$ conídios $\left./ \mathrm{ml}\right)$ e E. brejoensis (100 PPM). A taxa de sobrevivência de larvas de $A$. aegypti foi comparada com testes realizados com Fungos, óleos e controle.

\section{RESULTADOS E DISCUSSÃO}

\section{Extração e caracterização química dos óleos essenciais}

A hidrodestilação de folhas de C. leptophloeos produziu $0,08 \%$ de OE. A análise GC-MS do óleo revelou 55 constituintes, dos quais 46 que poderiam ser identificados de forma inequívoca representaram $97,8 \%$ do total de petróleo. Os principais componentes orgânicos foram os hidrocarbonetos sesquiterpênicos (média 46,4\%), seguidos dos hidrocarbonetos monoterpênicos $(43,4 \%)$, enquanto os constituintes menores foram sesquiterpenos oxigenados $(6,2 \%)$ e monoterpenos oxigenados $(1,5 \%)$. Os compostos principais no $\mathrm{OE}$ de folha de $C$. leptophloeos foram a-phellandrene (26,3\%), (E) caryophyllene (18\%), $\beta$-phellandrene (12,9\%), germacrene-D $(6 \%)$ e $\alpha$-humulene $(5,5 \%)$.

A hidrodestilação de folhas de E. brejoensis produziu 0,25\% de OE. Os 31 (trinta e um) compostos (Tabela 2) identificados no $\mathrm{OE}$ das folhas de E. brejoensis representaram 89,3\% dos componentes detectados nas análises GC. O OE continha principalmente sesquiterpenos $(62,66 \%)$ e sesquiterpenos oxigenados $(26,64 \%)$ e os principais constituintes foram $\Delta$-cadineno $(22,6 \%), \beta$-cariofileno $(14,4 \%)$, A-muurolol $(9,34 \%)$ a-cadinol $(8,49 \%)$ e Bicyclogermacrene $(7,93 \%)$. As identidades de cinco Constituintes do petróleo, representando o total de $9,92 \%$, não pôde ser confirmado. 


\section{Teste de contaminação dos conídios}

Nos testes de verificação de contaminação dos conídios por bactérias ou outros fungos deu negativo para ambos os testes (Figura 1), no meio ágar nutriente especifico para crescimento bacteriano, não foram identificadas colônias de bactérias. No meio BDA também não foram evidenciadas outras colônias fúngicas.

Figura 1: A - M. anisopliae em meio ágar nutriente (AN); B - M. anisopliae em meio batata dextrose ágar (BDA).
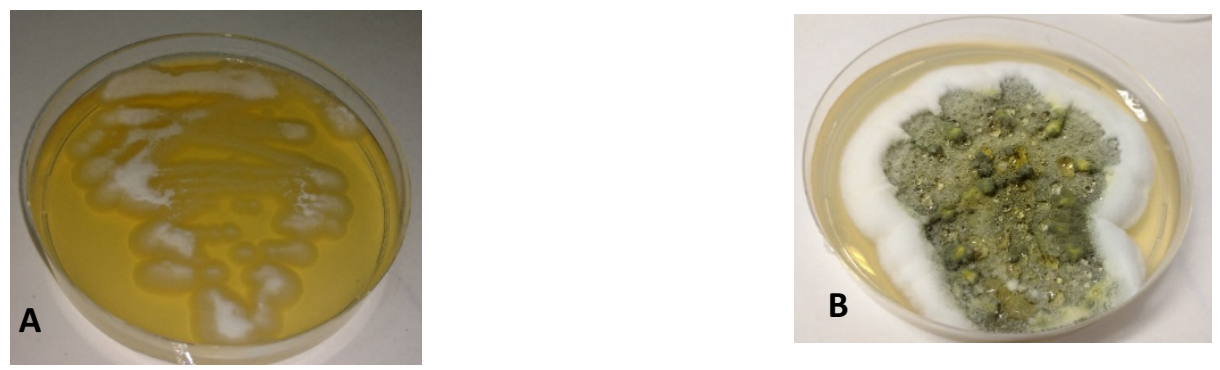

\section{Exposição do M. anisopliae aos óleos essenciais}

O M. anisopliae foi inoculado em meio BDA contendo altas dosagem dos OE's para se avaliar a toxidade deles ao fungo. As colônias do $M$. anisopliae geminaram entre $24-48 \mathrm{~h}$ após sua inoculação. A medição do seu crescimento se iniciou com $48 \mathrm{~h}$. Os OE's não apresentaram a capacidade de matar o fungo, porém reduziram o tamanho das colônias.

Tabela 1 - Crescimento do M. anisopliae em meio de cultura contendo OE's de Commiphora leptophloes e Eugenia brejoensis.

\begin{tabular}{ccccc}
\hline & $\begin{array}{c}\text { Concentração } \\
\mu 1 / \mathrm{ml}\end{array}$ & $\begin{array}{c}\text { Crescimento } \\
\text { radial }(\mathrm{cm})\end{array}$ & $\begin{array}{c}\text { Taxa de } \\
\text { crescimento (\%) }\end{array}$ & $\begin{array}{c}\text { Inibição de } \\
\text { Crescimento (\%) }\end{array}$ \\
\hline OE de C.leptophloes & 0,1 & 4,3 & 87,8 & 12,2 \\
& 1,0 & 4,0 & 81,6 & 18,4 \\
& 10,0 & 2,7 & 55,1 & 44,9 \\
\hline OE de E. brejoensis & 0,1 & 3,7 & 75,5 & 24,5 \\
& 1,0 & 3,1 & 63,3 & 36,7 \\
& 10,0 & 2,5 & 51,0 & 49,0 \\
\hline Controle & 0 & 4,9 & 100,0 & 0 \\
\hline
\end{tabular}

$\mathrm{O} \mathrm{OE}$ de E. brejoensis se mostrou mais tóxico ao M. anisopliae, inibindo $49 \%$ do crescimento radial da colônia, na concentração de $10 \mu \mathrm{l} / \mathrm{ml}$, enquanto o $\mathrm{OE}$ de $C$. leptophloeos na mesma concentração de $10 \mu \mathrm{l} / \mathrm{ml}$ inibiu 44,9\%. A medida que as concentrações dos OE's foram diminuídas, a inibição também diminui.

Nas figuras (2A e 2B) pode-se observar o crescimento do M. anisopliae por $168 \mathrm{~h} \mathrm{(7}$ dias), na presença e ausência dos OE's de C. leptophloeos e de E. brejoensis . 
Figura 2 - Exposição do Metarhizium anisopliae aos OE's das folhas de Commiphora leptophloes (A) e de Eugenia brejoensis (B).

A

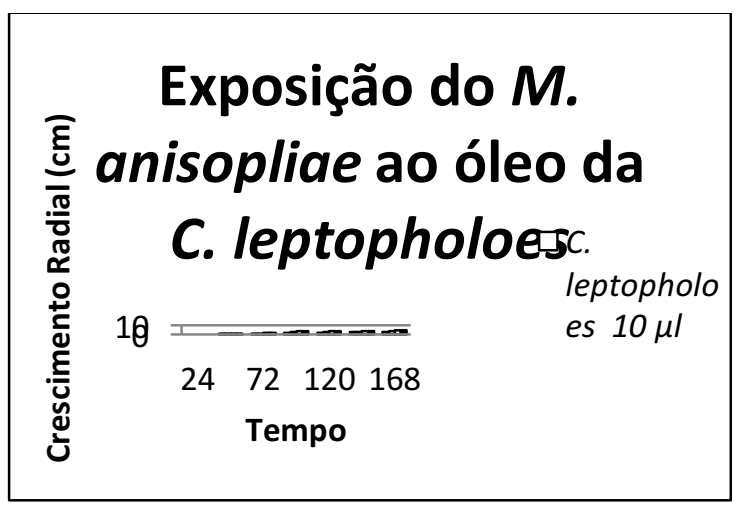

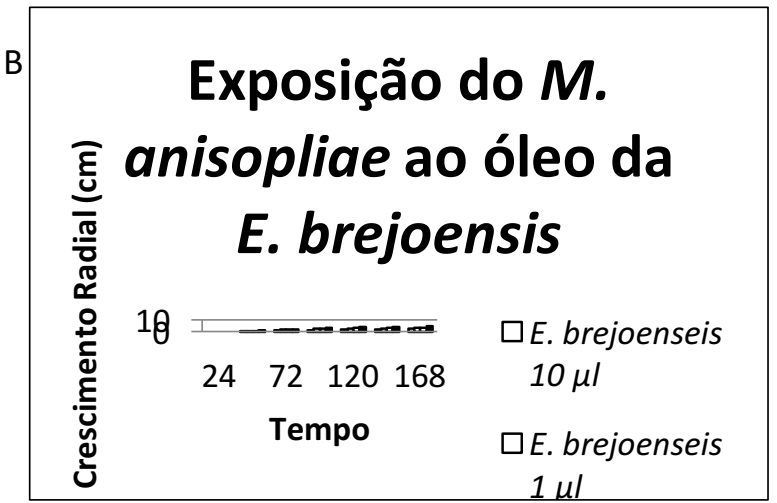

\section{Ensaio larvicida dos OE's}

Os efeitos larvicidas dos OE's se mostraram moderados para o início do quarto instar larval do $A$. aegypti. As concentrações dos óleos são inversamente proporcionais a taxa mortalidade das larvas, muito estudos sugerem um sinergismo com os compostos majoritários vendidos comercialmente ou até mesmo outras substancias. Nos ensaios larvicidas o $\mathrm{OE}$ de $C$. leptopholoes se destacou com sobrevivência de 50\% na concentração de 100 ppm, 85\% em 50 ppm e 100\% em 25 ppm, enquanto, o Oe de $E$. brejoenseis apresentou uma taxa de sobrevivência de $70 \%$ em 100 ppm e 100 em 50 e 25 ppm. Todos os tratamentos foram avaliados com 24 e $48 \mathrm{~h}$, a figura 3 foi montado com os números de larvas vivas após a exposição por $48 \mathrm{~h}$.

Figura 3 - Atividade larvicida com óleos essenciais das folhas de Commiphora leptopholes e de Eugenia brejoensis.

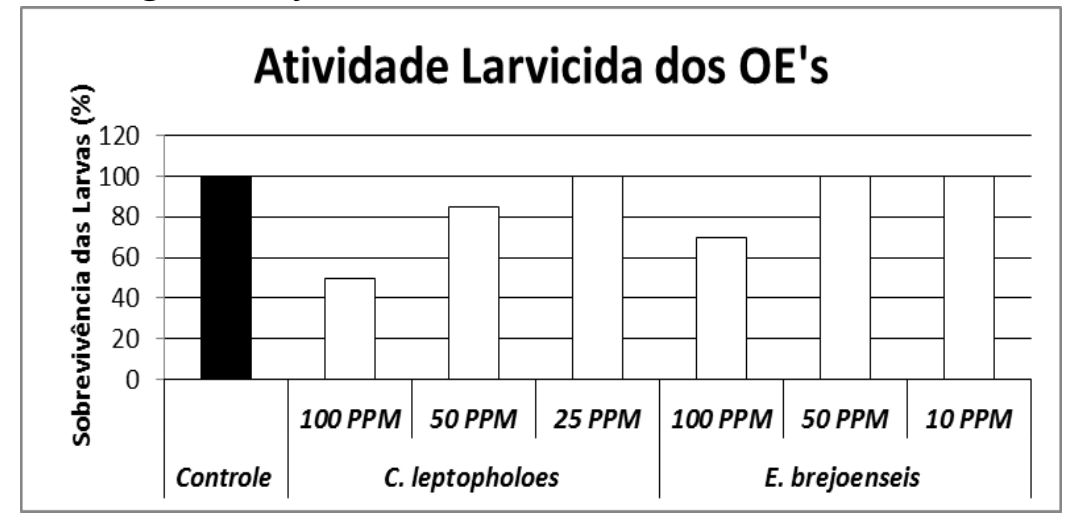

\section{Ensaio Larvicida do M. anisopliae}

O ensaio efetuado na concentração de $1 \times 10^{7}$ conídios/ml do fungo resultou na menor taxa de sobrevivência de larvas de A. aegypti (10\%) comparado com os resultados de sobrevivência dos demais ensaios. A maior porcentagem de sobrevivência ocorreu quando as larvas foram expostas à concentração do fungo de $1 \times 10^{9}$ conídios $/ \mathrm{ml}(50 \%)$. O controle negativo teve $100 \%$ de sobrevivência das larvas (Figura 4). 
Figura 4 - Atividade larvicida com soluções contendo conídios de Metarhizium anisopliae.

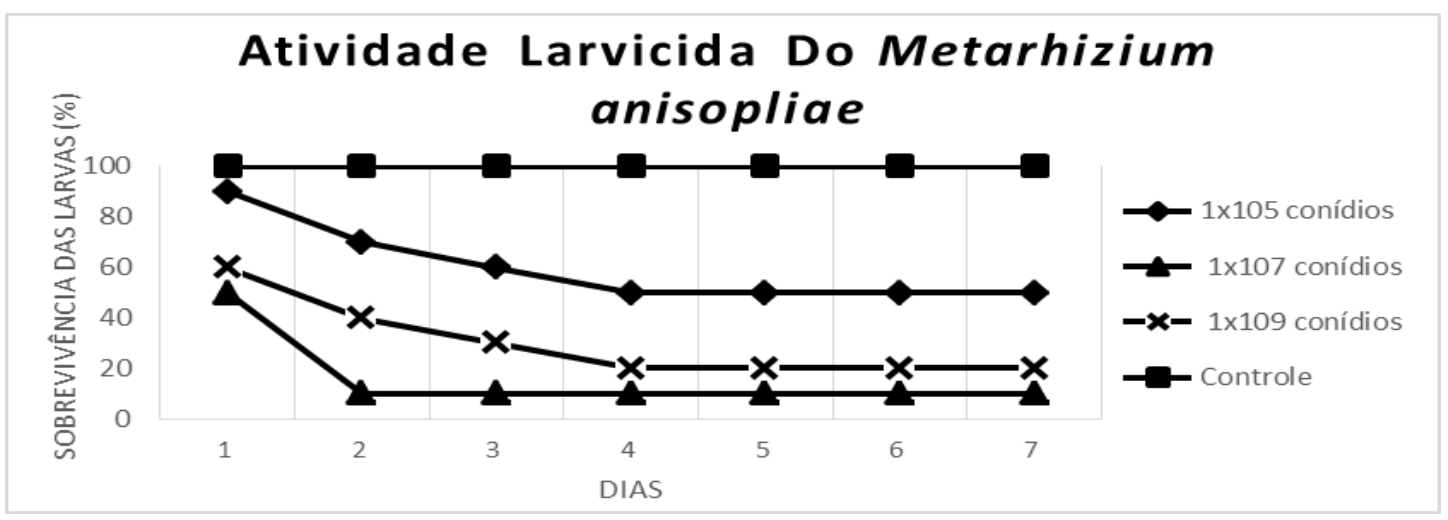

Ensaio Larvicida Sinérgico do M. anisopliae com os OE's das folhas de Commiphora leptopholeos e Eugenia brejoensis

Umas das propostas desse trabalho foi estudar o sinergismo do $M$. anisopliae combinado com OE's de C. leptopholeos ou E. brejoensis com intuito de potencializar os efeitos larvicidas. O efeito larvicida do fungo entomopatogénico ( $M$. anisopliae) e dos OE's (C. leptopholes e E. brejoensis) já foram comprovados em outros estudos, porém eles não têm a capacidade de chegar a 100\% de mortalidade larval do A. aegypti em baixas concentrações.

O OE de C. leptopholeos em sua maior concentração (100 ppm) apresentou uma sobrevivência de $50 \%$ das larvas após $48 \mathrm{~h}$. Quando a maior concentração do $\mathrm{OE}$ de $C$. leptopholeos foi $\mathrm{OE}$ de associada com a maior concentração do fungo obteve-se uma sobrevivência de $40 \%$ em 24 h, na mesma concentração o fungo matou $60 \%$ das larvas. Dos três tratamentos o mais eficaz foi a combinação de $1 \times 10^{7}$ conídios com 100 ppm do OE de C. leptopholoes que apresentou 10\% de sobrevivência em 48 h (Figura 5A).

$\mathrm{O} \mathrm{OE}$ de E. brejoensis em sua maior concentração (100 ppm) apresentou uma sobrevivência de $70 \%$ das larvas após $48 \mathrm{~h}$. Quando a maior concentração do OE de $E$. brejoensis foi associada com a maior concentração do fungo obteve-se uma sobrevivência de $30 \%$ em 24 h, na mesma concentração o fungo matou 60\% das larvas (Figura 5B). Dos três tratamentos os mais eficazes foram as combinações $1 \times 10^{5}$ e $1 \times 10^{7}$ conídios com 100 ppm do OE da E. brejoensis que apresentou $0 \%$ de sobrevivência em 48 h, porém em $24 \mathrm{~h}$ de experimento a combinação $1 \times 10^{7}$ conídios com 100 ppm de OE apresentou uma taxa de sobrevivência de $30 \%$ e $1 \times 10^{5}$ conídios com 100 ppm de OE apresentou $40 \%$ das suas larvas vivas. 
Figura 5 - Atividade larvicida com soluções contendo conídios de Metarhizium anisopliae e OE's das folhas de Commiphora leptophloes (A) e de Eugenia brejoensis (B).

A

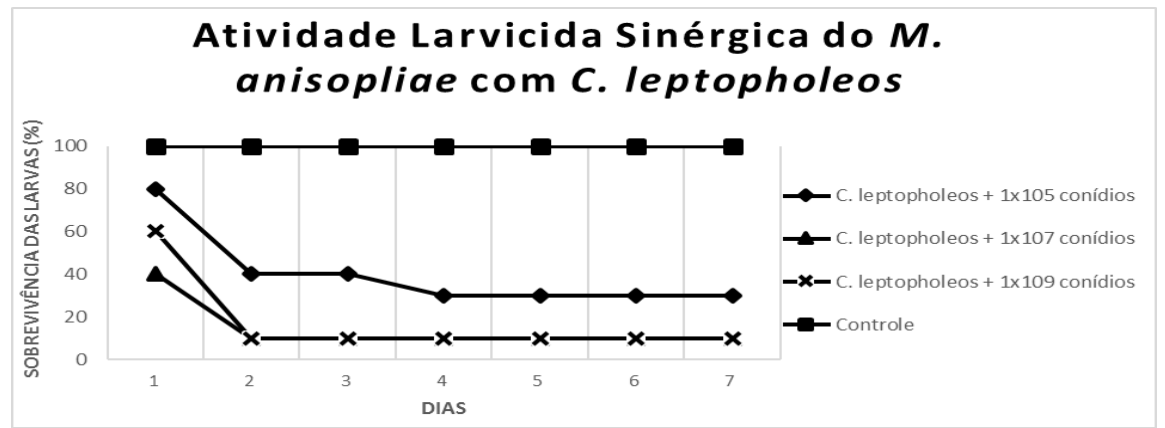

Atividade Larvicida Sinérgica do $M$. anisopliae com E. brejoensis

B

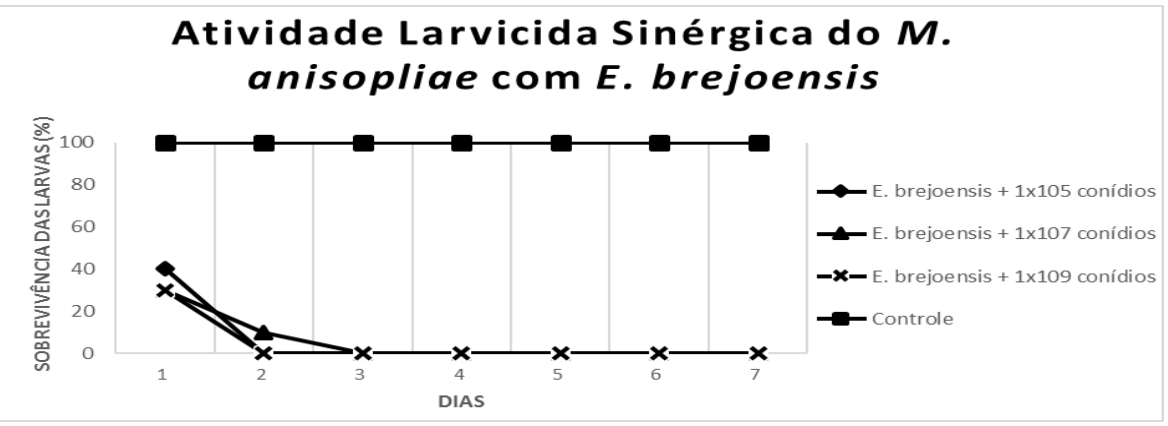

Os resultados se mostraram importantes tendo em vista a melhora do processo biotecnológico no controle das larvas do vetor de arboviroses $A$. aegypti. O efeito sinergético do entomopatogênico e $\mathrm{OE}$ aumentou de 30 a $50 \%$ a mortalidade das larvas, chegando até matar $100 \%$ das larvas em $48 \mathrm{~h}$.

Os óleos essenciais são constituídos por metabólitos secundários que são substâncias de defesa das plantas contra microrganismos fitopatógenos, insetos, dentre outros. Por essa característica eles tendem a ter um efeito larvicida. A interação larvafungo anormal foi atribuída ao fato de que $M$. anisopliae é um fungo terrestre e, portanto, não adaptado a um ambiente aquático. Por esse fato $M$. anisoplia não tem a capacidade de infectar as larvas. Na sua tentativa de se desenvolver no meio aquático ele provoca estresse oxidativo nas larvas do $A$. aegypti pela liberação de enzimas hidrolíticas (proteases, quitinases e lipases) no meio extracelular. Essas enzimas atuam tanto no desenvolvimento como na defesa do $M$. anisopliae. Quando associamos o fungo com os óleos essenciais ativamos os mecanismos de defesa, que irá aumentar a produção das enzimas hidrolíticas principalmente as quitinases, consequentemente aumenta virulência as larvas.

\section{CONCLUSÃO}

O sinergismo entre o fungo e OE's de plantas elevou a taxa de mortalidade de larvas de $A$. aegypti, vale ressalta que o fungo $M$. anisopliae combinado com o óleo essencial da E. brejoensis foram os mais eficientes. 


\section{REFERÊNCIAS}

COSTA, A. R. T.; AMARAL, M. F. Z. J.; MARTINS, P. M.; PAULA, J. A. M.; FIUZA, T. S.; RESVENZOL, L. M. F.; PAULA, J. R.; BARA, M. T. F. Ação do óleo essencial de Syzygium aromaticum (L.) Merr. \& L. M. Perry sobre as hifas de alguns fungos fitopatogênicos. Rev. Bras. de Plantas Med., v. 13, n.2, p.240-245, 2011.

Figueiredo, A.C., J.G. Barroso, L.G. Pedro \& J.J. C. Scheffer. Flavour Fragr. J. 23: 21326, 2008.

B. Gander, M.J. Blanco-Pryeto, C. Thomasin, C. Wandrey, D. Hunkeler, Coacervation/phase separation, in: J. Swarbrick, J.C. Boylan (Eds.), Encyc. of Pharm. Tec., Marcel Dekker Inc., Basel, New York, 1992, pp. 121-128.

GUERRA, M. S.; SOUZA, M. J. Como observar cromossomos: um guia de técnicas em citogenética vegetal, animal e humana. Ribeirão Preto SP. Ed. FUNPEC, p. 17-38, 2002.

Jin X, Chen Q, Tang SS, Zou JJ, Chen KP, Zhang T e Xiao XL (2009) Investigation of quinocetone induced genotoxicity in HepG2 cells using the comet assay, cytokinesisblock micronucleus test and RAPD analysis. Toxicol in Vitro 23:1209-1214.

Santos, J. W. A. B.; Efeito do óleo de nim na virulência e persistência do fungo entomopatogênico Metarhizium anisopliae contra larvas de Aedes aegypti. Dissertação (Mestrado em Produção Vegetal) - Centro de Ciências e Tecnologias Agropecuárias, Universidade Estadual do Norte Fluminense Darcy Ribeiro. p.64 2016.

SILVA, M. B.; MORANDI, M. A. B.; PAULA JÚNIOR, T. J.; VENZON, M.; FONSECA, M. C. M. Uso de princípios bioativos de plantas no controle de fitopatógenos e pragas. Inf. Agro., v. 31, n. 255, p. 70-77, 2010.

SOYLU, E. M.; KURT, S.; SOYLU, S. In vitro and in vivo antifungal activities of the essential oils of various plants against tomato grey mould disease agent Botrytis cinerea. Int. J. Food Microbiol., v. 143, n. 3., p. 183-189, 2010.

TYAGI, A. K.; MALIK, A. Antimicrobial potential and chemical composition of Eucalyptus globulus oil in liquid and vapour phase against food spoilage microorganisms. Food Chem., v. 126, p. 228-235, 2011.

\section{AGRADECIMENTOS}

Gostaríamos de agradecer ao CNPQ, ao Departamento de Bioquímica e Química Fundamental - UFPE e ao Laboratório de Biologia Molecular de Fungos Filamentosos UFRGS. 